\title{
Determinants of Life Partner Choice for University Girls
}

\author{
Samhaa Samir Ibrahim Mohammed ${ }^{1}$, Sherif Mohamed Attia Houria ${ }^{2}$ \\ ${ }_{1 \& 2}$ Department of Home Management and Institutions \\ Home Economic College, Menofia University, PO box 32631, Quesna, Egypt.
}

\begin{abstract}
This study examined the Determinants of life partner choice for university girls. Survey data drawn from the $\mathbf{1 0 0}$ girls in Saudi Arabia. The measures of study were demographic data form for girls, Determinants of life partner choice questionnaire. Results indicated that the first determinants importance of life partner choice for girls was health, personal was the second, Aesthetic was the third, followed by Religious, social, cultural and Economic, there was negative correlation between age and cultural determinants of life partner choice, there was no correlation between age and determinants of life partner choice, there was no correlation between family size and determinants of life partner choice, there was no correlation between father's education and determinants of life partner choice, there was no correlation between mother's education and determinants of life partner choice, there was positive correlation between income and health determinants of life partner choice, there was no correlation between income and determinants of life partner choice, there were differences between town and village in social determinants, where the girls who living in villages were better than Girls who living in cities, there were no differences between town and village in determinants of life partner choice, there were differences between girls who are studying theoretical study and girls who are studying practical study in aesthetic determinants, where practical study was better than theoretical, there were no differences between the practical and theoretical study of girls in Determinants of life partner choice.
\end{abstract}

Key Words: determinants, life partner choice, university girls

\section{INTRODUCTION}

Family is nucleus of society growing in it children until reaching puberty and maturity and since the birth, child receives a summary of experience of his family and the family with social concept works on her continued her survival and ingrained and stability by continuing social and cultural relations, and through education and training and family organizes child behavior and monitors his relations with other members of society, and family with simple form consists of husband, wife and unmarried sons, the family is the first cell in the society which is the basic unit of social construction and family Don't compose expect with marriage (Al ksas, 2008). Marriage is fungal and thinking about it is a request of healthy growth because it works to achieve a group of psychological, biological and social functions, including: forming a family, and having children, and to achieve psychological and social security, and to satisfy sexual instincts in legal (Anzi, 2009). So it is the legitimate relation which possible between women and men in family and society, which may be achieved through satisfaction, happiness and marital interaction, and this may be a relative, because this relation may have some psychosocial and social problems that lead to dissatisfaction (Al Gamaly, 2008). Human don't care in his life with any something, as much as caring his partner in life and a partner in the construction of marital home and happy family and perhaps marriage is the most important event in human life for man or woman, but there is a basic process before marriage, it is the choice of partner, good choice determines the future of marriage, the future of family and all society (Al Saaty, 2005). The most important two decisions in the human life is the choice of job and partner (husband or wife) and the final decision is a psychological process 
intervention in the responsibilities of the individual at his psychological health development, and in this context the choice of partner is the most important thing to research and study (Shamsan, 2009). marriage customs in Arab society depending on that mothers, sisters, relatives selecting a wife, and this is reasonable in a society respects its values and habits, but this does not prevent the man who get marry to choose his partner, and find the appropriate qualities such as her beauty or thinking or behavior or otherwise (Al Shamsi, 2013). Wife also dreaming who can understood her with her personality and privacy, and give her mind and respect and saturation of each intimate wishes which do not appear otherwise with legal marital relation, if husband failure in understanding the needs of her wife, and insist to treat her according to the prevailing stereotypes about women, we find him introducing things to her, he believes it will delight her, while she was waiting from him introducing other things to her, and vice versa on the part of women to men (Bassoal, 2008).

A happy marriage is a relative concept is not easy to measure and circulated, which means pleased with couple about their married life in general, marital happiness linked to successfully marital relation in their functions and tasks, such as secure the co-existence, housing and love, and do the psychological, emotional, sexual to them, as well as in having children and raising them, and do the requirements of the house and living, and achieve the requirements and several social roles (Mslaty, 2009). The marriage is the most important social systems, and the most impact on human life and society, it is the link between two sexes, and achieve the safety of social conditions and the survival of species, and improve the relations between men and women to the level of legitimacy, and regulating those relations according to human values, and with marriage the family will be composed, which is the basic unit of all societies, and a lot of scientific research were emphasized that the selection of a partner comes as the first step in influencing the efficiency of family formation (Al-Belhan, 2008). There are many of youth who will get marry if you asked him about the purpose marriage, you may not find has a clear answer to your question, or you may find it understands marriage with misunderstanding, each of the spouses and parents of wife the right to choose the matching and equivalents to her and achieve with him stability and harmony in the family and avoid the great discord and damage and humiliations, and that was the best and the first is that there is a convergence between the couple in the lineage, age and culture to avoid a gap between them, may be the cause of conflict and discord (Hmish, 2009).

The convergence and harmony to achieve marital compatibility keep the cohesion of married life and, by contrast, the consensus loss of some couples is one of the most important causes problems, and may not be causes physical, social or intellectual, but the absence of an understanding and harmony, this item requires flexibility in dealing patience and careful, and may not be achieved quickly, but requires some time and living together until both husband and wife discover the other character and begins to deal with it (Al Shamsi, 2013). And public life full of problems and pains and tragedies caused by marital life failure, and that could prevent if the man or woman choose a good partner, and every man or woman must have enough awareness to the dimension of step of marriage selection (Al saaty,, 2005). The urgency in the approval or choose by couple and the lack of investigation and accuracy in ask each other about other and his family is the most important reasons to fail marriages, you may find that the parents of wife are investigating thoroughly, but the parents of husband ask only about the easy things and phenomenon. In contrast, men or women exaggerate in the qualities required and whenever there is a man want to marry woman, they apologized so their age increased, and each other begin to offering concession cause a bad consequences, then the trip will be the most painful and ultimately pain final (Al-Amari, 2010). The lack of efficiency in the selection of a partner leads to alienation and cruelty, and have each other exalted over the other with his money or lineage or age or level of education, which leads to disharmony and 
spacing (Hmish, 2009). Success in marriage is a mainstay in the integrity of the life, in other way, the failure in marriage is often causes weak souls and the corruption of life and due to bad choice of partner, a bad choice linked to the difference in multiple aspects such as moral principles and literature or differing behavior or social and economic status or education or religion or other aspects of the position, including a negative impact on the interaction between the two couple and family in general (Al Belhan, 2008). Create a marriage or a happy marital relation between both men and women is a complicated thing or can be described as a double-edged sword, either success and calm family and either divorce which leads to splits in the family, some may ask if there was a way to maintain this eternal relation, the relation between man and woman is a contract and when this the contract agreement invalidated, the communication are being chill and thus adversely effect on relation with various aspects (Al Daef, 2010). The good and rational choice, leading to the decision to marry, it would serve to deepen the confidence of all men and woman that new life waiting them and they carry all positive intentions and mental preparations for the beginning of this stage in their lives and not to leave the selection process for the parents only, but should take responsibility and make the effort to investigate the required specifications that will achieve the initial assurances that indicate that there is consensus in the attributes and behavior among young people (Al Shamsi, 2013). It is clear from the foregoing that the marriage requires from the couple high adaptive ability and a good understanding of the marital relation, and if diminished or extinguished ability may lead to various problems and difficulties that impede their marital adjustment (AL Gamaly, 2008). Many marriages are exposed to emotional drought, who leads the relationship to fail, it may be a bad choice is an essential factor for the occurrence, and a bad choice linked to the difference in various aspects such as ethical principles and decency or social, economic or education or religion or other aspects of the place, including a negative impact on the interaction between the couple, it must be the right choice for a life partner, also the most important images of social choice, and the first thing a person does after making a marriage decision is to think of who will marry and shared his life, and determine the specifications of life partner (AL Anzi, 2009). It is clear that there are differences between people, every individual is different from the others in his level of (mental - personal - physical - emotional or mood) that would stabilize and the continuity of marriage and achieve emotional warmth of the couple and find suitable environment to raise children properly, bad marital choice may lead to a mismatch between couple and failure of marriage and then divorce happen (Al Belhan, 2008). Most of the previous studies on the determinants of life partner choice association with many variables in the choice, such as economic, social, personal, aesthetic, religious, cultural and health determinants. The life partner choice process is a mental process which human uses his mind when examining alternatives, so the four guiding research questions were as follows:

Research Question 1: What are the determinants of life partner and their order according to their priorities of university girls?

Research Question 2: Is there a relationship between demographic variables and the determinants of life partner choice?

Research Question 3: Is there a difference in the degree of life partner choice related to some demographic variables?

\section{Hypotheses}

Hypothesis 1: There is no statistically significant correlation relation between the determinants of life partner choice and their dimensions (economic determinants, social determinants, 
personal determinants, aesthetic determinants, religious determinants, cultural determinants, health determinants), and some demographic variables (age, family size - parents educational level - monthly income).

Hypothesis 2: There are significant differences in the determinants of life partner choice and their dimensions related to study type.

Hypothesis 3: There are significant differences in the determinants of life partner choice and their dimensions related to place of residence.

To study these hypotheses we conducted comparative descriptive analyses

\section{METHOD}

\subsection{Participants}

The sample consisted of 100 of university girls, who studying practical and theoretical, continuing in study and unmarried, from various social and economic levels, which selected in purposive way, the application was at Taibah University in Medina of Saudi Arabia on November $2014 \mathrm{AH}$.

\subsection{Measures}

The researchers designed the following data collection tools:

General data for the student form. It have included questions to indicate the age of girls with $(M=21.12, S D=1.486)$, the college were divided into two categories (Practical and Theoretical) encodes (1-2) respectively, then the place of residence and divided into two categories (Town - Village ) encodes (2-1) respectively, and the size of the family is also divided into categories (small family - moderate family - large family) encodes (3-2-1) respectively, and educational level both father and mother were divided into categories (do not know read and write - Intermediate Certificate - Certificate of High school or equivalent institutes - university Graduate) encodes (1-2-3-4-5-6), respectively, monthly income was divided into categories (less than 2000 - 2000 to less than 4000 - 4000 to less than 6000 more than 6000) encodes (1-2-3-4), respectively. Determinants of life partner choice questionnaire. The questionnaire included 44 phrases divided by 7 dimensions: economic determinants, social determinants, and personal determinants, aesthetic determinants, religious determinants, cultural determinants, health determinants.

Economic determinants: included 6 phrases $(\alpha=.70)$ included information on the level of economic and house level of life partner. And the answer is on a bilateral scale (yes - no) encodes (2-1).

Social determinants: included 6 phrases $(\alpha=.80)$ included information on the social relations of the life partner, number of friends, polygamy, and the quality of the relationship between the couple. The answer is on bilateral scale (yes- no) encodes (1-2).

Personal determinants: included 7 phrases $(\alpha=.90)$ about life partner information in terms of educational level and the age difference between the couple, the way of marriage and engagement period. The answer is on bilateral scale (yes- no) encodes (1-2).

Aesthetic determinants: included 6 phrases $(\alpha=.85)$ on the physical qualities of a life partner. The answer is on bilateral scale (yes- no) encodes (1-2).

Religious determinants: included 6 phrases $(\alpha=.85)$ described the case of a life partner the 
religious aspect. The answer is on bilateral scale (yes- no) encodes (1-2).

Cultural determinants: included 6 phrases $(\alpha=.90)$ described cultural of life partner. The answer is on bilateral scale (yes- no) encodes (1-2).

Health determinants: included 7 phrases $(\alpha=.90)$ described health of life partner information in general. The answer is on bilateral scale (yes- no) encodes (1-2).

\subsection{Analytic Strategy}

1. Percentages and duplicates

2. The mean and standard deviation

3. Cronbach's alpha coefficient.

4. Spearman coefficient

5. Pearson correlation coefficient

6. T test

7. One way ANOVA

Table 1. Girls Demographic Variables, Girls Family Relations and Girls Reproductive Health in Egypt and Saudi Arabia: Descriptive Statistics

\begin{tabular}{llllll}
\hline \multirow{2}{*}{ Variables } & \multicolumn{2}{l}{$N=100$} & & & \\
\cline { 2 - 6 } & $M$ & $S D$ & Range & nof items & $\alpha$ \\
\hline 1. Age & 21.12 & 1.486 & $18-27$ & - & - \\
2. Family size & - & - & $1-3$ & - & - \\
3. Father's education & - & - & $1-6$ & - & - \\
4. Mather's education & - & - & $1-6$ & - & - \\
5. Income & - & - & $1-4$ & - & - \\
6. Economic determinants & 10.07 & 0.998 & $1-3$ & 6 & .70 \\
7. Social determinants & 10.61 & 1.081 & $1-3$ & 6 & .80 \\
8. Personal determinants & 11.58 & 1.273 & $1-3$ & 7 & .90 \\
9. Aesthetic determinants & 11.08 & 1.002 & $1-3$ & 6 & .85 \\
10. Religious determinants & 10.84 & 1.061 & $1-3$ & 6 & .85 \\
11. Cultural determinants & 10.47 & 0.904 & $1-3$ & 6 & .90 \\
12. Health determinants & 13.17 & 1.111 & $1-3$ & 7 & .90 \\
13. Determinants of partner choice & 77.82 & 3.778 & $44-132$ & 44 & .90 \\
\hline
\end{tabular}

\section{RESULTS}

Hypothesis 1: There are no statistically significant correlation relationship between the determinants of life partner choice and their dimensions (economic determinants, social determinants, personal determinants, aesthetic determinants, religious determinants, cultural determinants, health determinants), and some demographic variables (age, family size parents educational level - monthly income).

Table 2. showed that there was no correlation between age and determinants of partner choice with their dimensions (economic determinants, social determinants, Personal determinants, 
aesthetic determinants, religious determinants and health determinants), there was negative correlation between age and cultural determinants $\mathrm{P}>.05$.

There was no correlation between family size and determinants of partner choice with all their dimensions (economic determinants, social determinants, personal determinants, aesthetic determinants, religious determinants, cultural determinants, health determinants).

There was no correlation between academic level and determinants of partner choice with all their dimensions (economic determinants, social determinants, personal determinants, aesthetic determinants, religious determinants, cultural determinants, health determinants).

There was no correlation between father's education and determinants of partner choice with all their dimensions (economic determinants, social determinants, personal determinants, aesthetic determinants, religious determinants, cultural determinants, health determinants).

There was no correlation between mother's education and determinants of partner choice with all their dimensions (economic determinants, social determinants, personal determinants, aesthetic determinants, religious determinants, cultural determinants, health determinants).

There was no correlation between income and determinants of partner choice with their dimensions (economic determinants, social determinants, personal determinants, aesthetic determinants and religious determinants), there was positive correlation between income and health determinants $\mathrm{P}>.05$.

Hypothesis 2: There are significant differences in the determinants of life partner choice and their dimensions related to place of residence.

Table 3. Showed that there were no differences between girls who residing in villages and Girls who residing in cities at determinants of partner choice and their dimensions (economic determinants, personal determinants, aesthetic determinants, religious determinants, cultural determinants and health determinants).

There were statistically significant differences between town and village in social determinants $\mathrm{P}>.05$, where the average degree of girls who living in villages was better than girls who living in cities. 


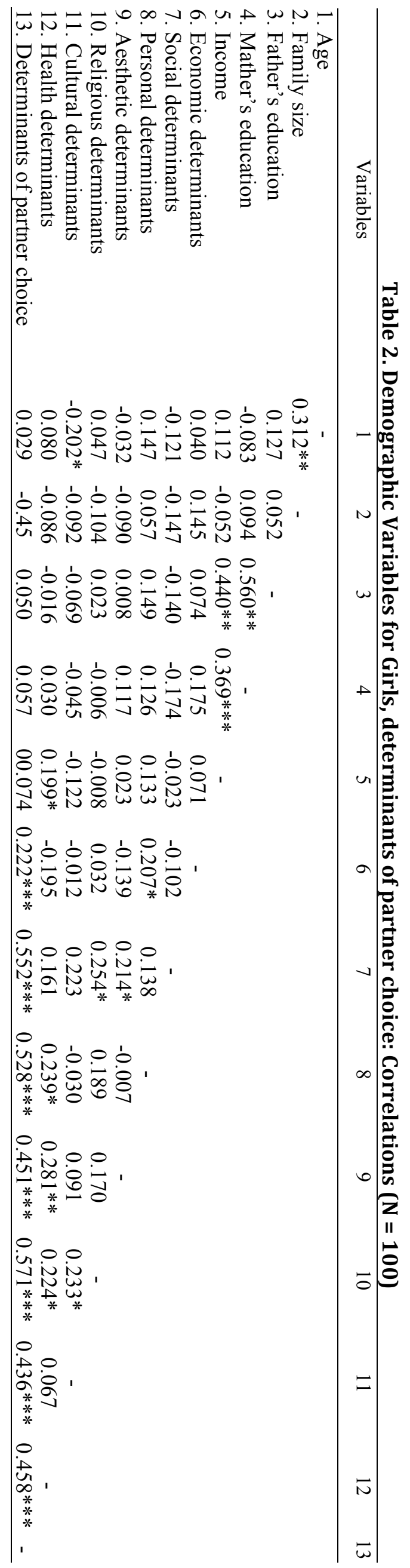


Table 3. Structure of determinants of partner choice related to Residence

\begin{tabular}{|c|c|c|c|c|c|c|}
\hline \multirow{3}{*}{ Variation source } & \multirow{2}{*}{\multicolumn{2}{|c|}{$\begin{array}{l}\text { City (T) } \\
N=93\end{array}$}} & \multirow{2}{*}{\multicolumn{2}{|c|}{$\begin{array}{l}\text { Village }(\mathrm{V}) \\
N=7\end{array}$}} & \multirow{2}{*}{\multicolumn{2}{|c|}{ Independent samples $t$ test }} \\
\hline & & & & & & \\
\hline & $\bar{M}$ & $S D$ & $M$ & $S D$ & $t$ value & T VS V \\
\hline Economic determinants & 10.09 & 1.007 & 9.86 & 0.900 & 0.583 & $n s$ \\
\hline Social determinants & 10.55 & 1.079 & 11.43 & 0.787 & -2.113 & * \\
\hline Personal determinants & 11.60 & 1.270 & 11.29 & 1.380 & 0.632 & $n s$ \\
\hline Aesthetic determinants & 11.12 & 1.009 & 10.57 & 0.787 & 1.399 & $n s$ \\
\hline Religious determinants & 10.83 & 1.090 & 11.00 & 0.577 & -0.412 & $n s$ \\
\hline Cultural determinants & 10.43 & 0.914 & 11.00 & 0.577 & -1.622 & $n s$ \\
\hline Health determinants & 13.20 & 1.089 & 12.71 & 1.380 & 1.127 & $n s$ \\
\hline Determinants of partner choice & 77.82 & 3.831 & 77.86 & 3.237 & -0.027 & $n s$ \\
\hline
\end{tabular}

Note: coefficients not marked with asterisks were not significant

$* p<.05$.

Hypothesis 3: There are significant differences in the determinants of life partner choice and their dimensions related to study type.

Table 4. Showed that there were no differences between Girls who are studying theoretical study and girls who are studying practical study at determinants of partner choice with their dimensions (economic determinants, Social determinants, personal determinants, religious determinants, cultural determinants, health determinants), where the average degree of practical study was convergent with theoretical study. There were statistically significant differences between girls who are studying theoretical study and girls who are studying practical study in aesthetic determinants $P>.01$, where the average degree of practical study was better than theoretical.

Table 4. Structure of determinants of partner choice related to Study Type

\begin{tabular}{|c|c|c|c|c|c|c|}
\hline \multirow[t]{2}{*}{ Variation source } & \multicolumn{2}{|c|}{$\begin{array}{l}\text { Practical (P) } \\
N=77\end{array}$} & \multicolumn{2}{|c|}{$\begin{array}{l}\text { Theoretical (T) } \\
N=23\end{array}$} & \multicolumn{2}{|c|}{ Independent samples $t$ test } \\
\hline & $\bar{M}$ & $S D$ & $M$ & $S D$ & $t$ value & P VS T \\
\hline Economic determinants & 10.05 & 1.050 & 10.13 & 0.815 & -0.330 & $n s$ \\
\hline Social determinants & 10.65 & 1.073 & 10.48 & 1.123 & 0.664 & ns \\
\hline Personal determinants & 11.66 & 1.382 & 11.30 & 0.765 & 1.186 & ns \\
\hline Aesthetic determinants & 11.23 & 0.902 & 10.57 & 1.161 & 2.913 & $* *$ \\
\hline Religious determinants & 10.91 & 1.054 & 10.61 & 1.076 & 1.194 & ns \\
\hline Cultural determinants & 10.40 & 0.907 & 10.70 & 0.876 & -1.370 & ns \\
\hline Health determinants & 13.26 & 1.056 & 12.87 & 1.254 & 1.487 & ns \\
\hline Determinants of partner choice & 78.17 & 3.891 & 76.65 & 3.171 & 1.706 & ns \\
\hline
\end{tabular}

Note: coefficients not marked with asterisks were not significant

${ }^{* *} p<.01$

\section{DISCUSSION}

The first determinants importance of life partner choice for girls was health, personal was the second, Aesthetic was the third, followed by Religious, social, cultural and Economic, because girls want a good married life and birth healthy children.

Some studies showed that the most common marital selection criteria for youth were religious commitment, the reputation of family, beauty, morality, income and afford ability respectively (Al-Anzi, 2009). The most important determinants among females were emotions (Al Zamil, 
2007). University youth prefer mutual attraction, good mood, good literature and morals, religious commitment and good health respectively (Al Shamsan and Darwish, 2009).The favorite determinant for university girls was economic aspects (Asma Al Rwaili, 2006). The factors leading to marriage were religious factor, health factor, social factor, psychological factor and economic factor respectively (Nazmi Abu Mustafa, 2007).

Marital adjustment elements are arranged from the viewpoint of university girls as follows: emotional maturity, social and emotional support of the family, religious element, cultural element, convergence in age, educational level and economic level (Wafaa Abdul Razak, 2009). The older girls in college waived for cultural determinants that are interested in the life partner more than younger girls, as a result of few opportunities to marry because of the customs and traditions of Arab societies, while age had not any an influential role on the determinants of economic factors, social, personal, aesthetic, religious and health determinants. This result agreed with Nazmi Abu Mustafa who showed that There were no differences between the factors leading to marriage according to age (Nazmi Abu Mustafa, 2007).

There was no role of Number of members of the girl's family or educational level of her Parents in determining the determinants of life partner and their dimensions, while the increase of the monthly income for a family girl had a positive role in health determinants for a life partner, Some studies showed that There were no differences between the factors leading to marriage according to variables: age, educational level and income level, while found differences in health factor according to income in favor of the lowest income (Nazmi Abu Mustafa, 2007). When parents' education increased, Awareness of parents in life partner choice was the best (Asma Al Rwaili, 2006).

Girls who live in villages more capable, deeper and more positive in social determinants than girls cities. This may be due because the villages are still is keen on the customs and traditions of marriage, while the cities affected by societal development and opening to the outside world The university girls in the practical study were more ability to develop aesthetic determinants than girls in theoretical study.

\section{CONCLUSION}

Establishment family Counseling Centers, providing extension services of marriage. Raise the community awareness of the importance of proper marital choice by do many of educational symposiums for all segments of society. Recommendation that the curriculum include in secondary education and university courses and some topics about family and marriage. Do more research to choose a life partner and family formation.

\section{Reference}

Abdul Razzaq, wafaa (2009). the elements of marital adjustment from the perspective of the students married and unmarried, Faculty of Education at King Saud University in the light of the psychological and cognitive variables. (Ph. D), King Saud University, Saudi Arabia.

Abdul Razzaq, Wafaa (2009). The elements of marital adjustment from the perspective of married and unmarried students at Faculty of Education of King Saud University in the light of the psychological and cognitive variables, (Ph. D), Department of Psychology, College of Education, King Saud University, Riyadh, Saudi Arabia.

Abu Mustafa, Nazmi (2007). The factors leading to marry outside the clan (a field study on a sample of Palestinian Bedouin community). Journal of the Islamic University of Gaza (Humanities Series), vol 1. 
Al Amari, Yahya (2010). A Journey of success between the couple. Jeddah: cultural papers house for publication and distribution.

Al Anzi, Farhan (2009). The role of thinking and the criteria for selecting a partner and some demographic variables in achieving marital compatibility level among a sample of Saudi society methods. (Ph. D), Psychology, College of Education, Umm Al Qura University, Saudi Arabia.

Al Belhan, Isa (2008). Marital choice by university students' perceptions. a comparative study among young Kuwaitis and young Americans, Journal of educational, social and humanitarian, Umm Al Qura University, Saudi Arabia.

Al Daef, Khalid (2010). Marital adjustment and its relationship to quality of life. Psychological counseling, Faculty of Education, University of Aleppo: Syria.

Al Gamaly, Fawzia (2008). Marital adjustment among couples Omani in light of some of the variables. Journal of Educational and Psychological Studies, Sultan Qaboos University, Oman.

Al Khashab, Mustafa (2001). The Book of the family meeting. Cairo: Arab Thought house for printing, publishing and distribution.

Al ksas, Mohammed (2008). The Science of the family meeting. Egypt: Amer for printing and publishing.

Al Rwaili, Asma (2006). Social and economic factors associated with the patterns of marriage. (MSc). King Saud University, Riyadh.

$\mathrm{Al}$ saaty, Samia (2005). The choice of marriage and social change. General Egyptian Book Organization: Cairo.

Al Saban, Abeer (2009). Marital adjustment in the light of some personality traits among a sample of Saudi wives in Mecca. Presents to "Fourteenth Congress psychological guidance Conference" psychological counseling for development in light of the overall quality (future) orientations, Ain Shams University, Cairo.

Al Shamsi, Maysaa (2013): A successful marriage manual. Emirates: Gulf of United Arab Studies.

$\mathrm{Al}$ Zamil, Al Jawhara (2007). Factors influencing the views of young people for marriage university field study of a sample of students from the Faculty of Arts. (Ph. D), King Saud University, Riyadh, Saudi Arabia.

Al-Bakri, Mohamed (2002). Encyclopedia, Fiqh and the judiciary in the personal status. Cairo: Mahmoud House for publication and distribution.

Bassoal, Amal (2008). Marital adjustment and its relationship to saturation expected and the actual needs of mutual emotional between spouses. (MSc), Saud Islamic University, Riyadh.

Carter (2004). Choice freedom. Welfare 22: 61-81, doi: 10.1007 / s00355-003-0277-z.

Hmish, Bader (2009). Marital disputes (causes - solutions). Publishing House: Jordan.

lamry, Alia (2003). Some social and cultural factors leading to early divorce. (MSc), Faculty of Arts, King AbdulAziz University, Saudi Arabia.

Mslaty, Ayman (2009).The Book of marital happiness - commitment and art. Read house for printing, publishing and distribution: Syria.

Shamsan, Munira and Darwish, Zainab (2009). Criteria for choosing a life partner and their relationship to some psychological variables and the demo bibliographic among university students Saudis and Egyptians. (PhD), King Saud University, Saudi Arabia.

Shamsan, Munira and Darwish, Zainab (2009). Criteria of life partner choice and their relationship to some psychological and the demographic variables among Saudi and Egyptian university students. (Ph. D), Department of Psychology, Faculty of Arts and Faculty of Education, Cairo University and King Saud University, Saudi Arabia.

Zafiri, Abdel Wahab, Abdel Latif, Khalifa and Hosni, Hamdi (2002). The social and psychological causes of divorce in Kuwait at the beginning of the third millennium. The center of the Gulf and Arabian Peninsula Studies: Kuwait. 